\title{
Creating a Network of High-Quality Skilled Nursing Facilities: Preliminary Data on the Postacute Care Quality Improvement Experiences of an Accountable Care Organization
}

\section{Citation}

Lage, Daniel E. 2017. Creating a Network of High-Quality Skilled Nursing Facilities: Preliminary Data on the Postacute Care Quality Improvement Experiences of an Accountable Care Organization. Doctoral dissertation, Harvard Medical School.

\section{Permanent link}

http://nrs.harvard.edu/urn-3:HUL.InstRepos:40621378

\section{Terms of Use}

This article was downloaded from Harvard University's DASH repository, and is made available under the terms and conditions applicable to Other Posted Material, as set forth at http:// nrs.harvard.edu/urn-3:HUL.InstRepos:dash.current.terms-of-use\#LAA

\section{Share Your Story}

The Harvard community has made this article openly available.

Please share how this access benefits you. Submit a story.

\section{Accessibility}


Scholarly Report submitted in partial fulfillment of the MD Degree at Harvard Medical School

Date: 25 January 2017

Student Name: Daniel E. Lage, MSc, MBA

Scholarly Report Title: Creating a Network of High-Quality Skilled Nursing Facilities:

Preliminary Data on the Postacute Care Quality Improvement Experiences of an Accountable Care Organization

Mentor Name(s) and Affiliations:

Current: David C. Grabowski, PhD- Professor of Health Care Policy, Harvard Medical School

Former: D. Clay Ackerly, MD, MSc- Chief Medical Officer Privia Health (formerly of Massachusetts General Hospital / Partners Health Care)

Collaborators, with Affiliations:

Donna Rusinak, BA, Partners HealthCare

Darcy Carr, MPH, MBA, Partners HealthCare 


\section{Creating a Network of High-Quality Skilled Nursing Facilities: Preliminary Data on the Postacute Care Quality Improvement Experiences of an Accountable Care Organization}

Daniel E. Lage, MSc, ${ }^{*}$ Donna Rusinak, BA, ${ }^{*}+\ddagger \S$ Darcy Carr, MPH, MBA, $\ddagger \S$ David C. Grabowski, $\mathrm{PhD}, *$ and D. Clay Ackerly, MD, MSc* $+\S$

From the *Harvard Medical School; +Division of General Internal Medicine, Massachusetts General Hospital; $¥$ Partners HealthCare; and §Partners Continuing Care, Boston, Massachusetts.

Postacute care (PAC) is an important source of cost growth and variation in the Medicare program and is critical to accountable care organization (ACO) and bundled payment efforts to improve quality and value in the Medicare pro- gram, but ACOs must often look outside their walls to identify high-value external PAC partners, including skilled nursing facilities (SNFs). As a solution to this problem, the integrated health system, Partners HealthCare System (PHS) and its Pioneer ACO launched the PHS SNF Collaborative Network in October 2013 to identify and partner with high- quality SNFs. This study details the method by which PHS selected SNFs using minimum criteria based on public scores and secondary criteria based on selfreported measures, describes the characteristics of selected and nonselected SNFs, and reports SNF satisfaction with the collaborative. The selected SNFs $(n=47)$ had significantly higher CMS Five-Star scores than the nonselected SNFs $(\mathrm{n}=93)(4.6$ vs 3.2, $\mathrm{P}<.001)$ and were more likely than nonselected SNFs that met the minimum criteria $(n=35)$ to have more than 5 days of clinical coverage $(17.0 \%$ vs $2.9 \%, \mathrm{P}=.02)$ and to have a physi- cian see admitted individuals within $24(38.3 \%$ vs $17.1 \%, \mathrm{P}=.02)$ and 48 hours (93.6\% vs $80.0 \%, \mathrm{P}=.03)$. A survey sent to collaborative SNFs found high satisfaction with the pro- cess (average satisfaction, 4.6/5, with 1 $=$ very dissatisfied and $5=$ very satisfied,$n=19$ ). Although the challenges of improving care in SNFs remain daunting, this approach can serve as a first step toward greater clinical collaboration between acute and postacute settings that will lead to better outcomes for frail older adults. 


\section{Description of Student Role in the Work:}

I spent the summer of 2014 working with Dr. Clay Ackerly (formerly of HMS/MGH) and Prof. David Grabowski (current mentor) on this project, studying Partners Healthcare's attempts to create a high-quality network of skilled nursing facilities (SNF). The Partners SNF Collaborative Network already existed when I came to the project, but this innovative quality improvement model had not been systematically described or evaluated. My role was to be the primary leader of the efforts to describe and evaluate the SNF collaborative network. I first completed a literature review on the use of skilled nursing facilities (SNFs). I also attended multiple staff meetings at MGH and Partners HealthCare where issues of SNF use were discussed in order to learn about the relevant issues. I consulted both with staff at Partners HealthCare and with Prof. David Grabowski about the methodology and design of the study.

The bulk of my work consisted of analyzing data on the SNFs that applied to be a part of the Partners SNF network, in order to see the differences between those selected and not selected. This data included publicly reported information, private information submitted by the SNFs, as well as information within the Partners database. I then conducted all statistical analyses independently, and drafted the initial manuscript. I received detailed feedback from all of the co-authors, and then completed the final draft. We prepared the manuscript for the Journal of the American Geriatrics Society under their "Innovative Care Delivery Models: Preliminary Data" section, and the manuscript was accepted and published in 2015.

\section{Citation:}

Lage DE, Rusinak D, Carr D, Grabowski DC, Ackerly DC. Creating a network of high-quality skilled nursing facilities: preliminary data on the postacute care quality improvement experiences of an accountable care organization. J Am Geriatr Soc. 2015 Apr;63(4):804-8. doi: 10.1111/jgs.13351. PubMed PMID: 25900492. 